COMITÉ INTERNATIONAL

\title{
DÉCĖS DE QUATRE COLLABORATEURS DU CICR
}

En l'espace de deux mois, le CICR a perdu quatre de ses collaborateurs, morts dans l'accomplissement de leur mission humanitaire. Trois étaient Suisses, l'un était Africain; tous étaient animés de cet esprit de dévouement et de sacrifice, qui pousse certains à l'aide et à l'assistance de leur prochain dans la détresse. Hautement conscients des responsabilités qu'on leur avait confiées, ils ont ainsi bravé les dangers et rencontré la mort, apportant un merveilleux témoignage de fraternité humaine.

Louis Gaulis, décédé d'un accident le 29 mars au Liban, était un poète et un auteur dramatique connu, né en 1932, marié et père de deux enfants. Il avait fait plusieurs missions pour le CICR: au Bangladesh en 1972, puis au Vietnam et à Chypre; il était arrivé au Liban en janvier dernier. A ses dons artistiques s'alliait une nature d'une rare richesse, qui attirait l'amitié. Sa perte a été ressentie avec un immense chagrin par tous ceux qui le connaissaient.

André Tièche, né en 1947, était un homme accompli. Rien d'académique en lui, mais une grande chaleur humaine, beaucoup de finesse, un brin de malice, de la générosité en tout. Il avait une vocation spontanée pour les tâches humanitaires et avait servi le CICR en Angola en 1976, au Liban en 1977; après quelques semaines au siège du CICR à Genève, il était reparti pour la Rhodésie au début de 1978, plein d'ardeur et de courage, pour une mission dont il mesurait les risques. Il ne devait pas en revenir et il laisse un fils âgé de douze ans.

Alain Bieri, titulaire de trois diplômes universitaires, était un jeune homme modeste et discret, intelligent, aimable et spirituel. Né en 1945, il avait interrompu sa carrière dans l'enseignement, pour se mettre au service du CICR en janvier 1977, et apporter ainsi sa contribution à l'œuvre de la Croix-Rouge. Il avait d'abord été affecté à la délégation 
du CICR à Damas. Il était parti le 9 mai pour sa nouvelle mission en Rhodésie, où dix jours plus tard il devait trouver la mort.

Charles Chatora était un homme très jeune, marié, originaire d'Umtali. C'est là qu'il s'était engagé au service de la délégation du CICR en Rhodésie/Zimbabwe. Très ouvert, intelligent, entreprenant, il s'adonnait de tout son cceur à son travail, qui le passionnait. Il était heureux d'avoir une activité humanitaire dans une région et pour des gens qu'il connaissait bien.

Réuni, jeudi 25 mai 1978, sous la présidence de M. Alexandre Hay, président du Comité international de la Croix-Rouge, le Conseil exécutif du CICR a pris connaissance d'un premier rapport sur l'assassinat en Rhodésie/Zimbabwe de ses deux délégués, André Tièche et Alain Biéri, et de leur collègue africain, Charles Chatora. Ce rapport fait craindre que cet acte ignoble et lâche visait délibérément la mission humanitaire de la Croix-Rouge. Il revêt par conséquent la plus haute gravité.

Le CICR mettra tout en œuvre pour connaître la vérité sur les circonstances exactes de ce triple meurtre et sur ses auteurs, qui restent pour l'instant inconnus. Le Directeur des Opérations du CICR, M. JeanPierre Hocké, en mission en Afrique australe, a été chargé d'intervenir auprès des plus hautes autorités responsables des parties au conflit, pour les inviter à faire toute la lumière sur ce drame et leur demander de prendre immédiatement toutes mesures en vue d'assurer le respect absolu du signe de la Croix-Rouge et la sécurité des délégués du CICR, afin qu'ils puissent poursuivre leurs activités humanitaires en Rhodésie/ Zimbabwe. En outre, le Conseil exécutif a approuvé la décision, prise par la direction du CICR, d'envoyer dans ce pays un expert suisse en criminologie, ainsi qu'un de ses délégués-juristes, spécialiste du droit anglo-saxon.

Enfin, le Comité international de la Croix-Rouge lance un appel solennel à tous les Etats signataires des Conventions de Genève pour leur rappeler qu'en adhérant à celles-ci, ils ne s'engagent pas seulement à les respecter mais aussi à les faire respecter. Rien ne doit être épargné pour que l'emblème de la Croix-Rouge et ceux qui le portent continuent d'être protégés au cceur même des combats, faute de quoi le dernier espoir de mettre des limites à l'inhumanité de la guerre s'évanouira. 
Le Conseil exécutif du CICR a tenu à s'associer à la grande douleur des familles et à leur exprimer sa profonde sympathie.

Les dépouilles mortelles des délégués suisses décédés ont été rapatriées à Genève. Le CICR a rendu un hommage ému à leur mémoire, lors des cérémonies funèbres. En l'absence du président du CICR, M. H. Huber, vice-président, a prononcé une allocution lors du service célébré pour $M$. Gaulis. Une brève cérémonie, sur l'aéroport de Genève, a marqué le retour des délégués de Rhodésie/Zimbabwe. En présence des familles des défunts, le président du CICR, M. A. Hay, entouré des dirigeants du CICR, de la Ligue et d'un représentant des autorités fédérales suisses, a déposé une gerbe de fleurs sur les cercueils recouverts du drapeau de la Croix-Rouge. En Rhodésie, la délégation a participé aux obsèques de $M$. Chatora.

Le CICR ne pourra jamais oublier que ses délégués ont payé de leur vie la cause de la Croix-Rouge, qu'ils ont servie avec dévouement, avec courage et enthousiasme.

Le CICR, après l'annonce de ces décès, a reçu, du monde entier, des témoignages de sympathie et des condoléances. Le Secrétaire général de l'ONU, M. K. Waldheim, des gouvernements, des Sociétés de la CroixRouge, des organismes internationaux et aussi de simples particuliers ont écrit au CICR pour prendre part à son deuil. 